\title{
Steven Holl: From the Hinged Space to the Chromatic Space
}

\author{
M. Teresa Díez Blanco
}

\begin{abstract}
By 1983, Steven Holl had begun experimenting with so-called 'hinged space' in a series of apartments in Manhattan based on a planar and linear vision of architecture. Therefore, a parallel could be drawn with De Stijl group and their neoplastic paintings. Projects like housing in Fukuoka and Storefront gallery are evolved examples of the same ideas. The creation of 'chromatic space'-another term coined by Holl - is analyzed through D.E. Shaw and Sarphatistraat offices renovation, where the phenomena of spatial colour reflection are explored, thereby establishing new points in common with the chromatic architecture of the Dutch group.
\end{abstract}

Keywords Steven Holl • Neoplasticism • Planar architecture

By 1983, Steven Holl had begun experimenting with so-called 'hinged space' in a series of apartments in Manhattan, such as the Cohen apartment and the XYZ of the MoMA tower, which featured partitions with moving parts fully integrated into the wall, simulating planes rotating on a vertical axis. The fact that these panels had unusual shapes (inverted L or T) helped to further blur the concepts of doors and partitions when in use.

In his book Parallax, the American architect defined hinged space as the transformation of an autonomous space into an interactive space consisting of 'participating walls', which he himself described as a hybrid between fixed and hinged walls, whose function was to rearrange the domestic habitat in order to suit user needs. The aim was, in short, to create a dynamic space with movement, as set by deconstructivist trends (according to Holl this was unsuccessful, as it addresses changing architecture in form but is static in its execution): "The then-current polemics of 'deconstruction' led other designers to create twisted grids, shards of walls, and tortured folds. When their geometries were built, space was frozen into a caricature of the dynamic" (Holl 2000, 230).

M.T. Díez Blanco ( $₫)$

Escuela Técnica Superior de Arquitectura de Barcelona, Universidad Politécnica de Cataluña,

Barcelona, Spain

e-mail: mt10blanco@coac.net

E. Castaño Perea and E. Echeverría Valiente (eds.), Architectural Draughtsmanship, https://doi.org/10.1007/978-3-319-58856-8_76 
Therefore, the architect created a number of domestic areas with moving partitions, thereby altering the perception of the created space as a result of changing the parallax: term that he adapted to the architectural and urban field, defining it as "the change in the arrangement of surfaces defining space due to the change position of a viewer" (Holl 2003, 80). The approach to architecture in which what matters is the perceptual experience of the viewer, implying a manner of operating that starts with a preview drawn in perspective prior to the plans. That is to say, during the design process the exploration of the space from the closest possible viewpoint to direct vision is used, avoiding abstract planar representations. As explained by Steven Holl himself: "Instead of a priori plans projected later into perspective drawings, perspective views are made and cast backwards into plan fragments" (Holl 2003, 80).

In the 1983 renovation of the Cohen apartment, the existing walls of the rooms were torn down leaving the old beam system exposed. Holl chose not to partition the main sections, thus creating a sequence of concatenated spaces made up of the dining room, living room and study, framed only by the structure of pillars and girders.

In terms of design, the proposal was based on three basic compositional types: linear, volumetric and planar. Therefore, the dining area was dominated with furniture in linear forms, the living room featured volumetric motifs, and both the studio and bedroom featured planar compositions based on rectangles and squares. In fact, for the partition between these last two areas, two rectangular wall segments were cut out that could be opened or closed, both visually (by way of a window) and physically (by way of a pivoting door), communicating the areas which would constitute the source of the hinged space (Fig. 1).

Lastly, since the views from the apartment are only nearby skyscrapers, the architect wanted to give the interior space its own horizon in the form of a sheet metal strip running along the vertical elements (walls, pillars and hinged panels), chromatically dividing them into two distinct parts: the plaster below the strip is cream coloured, while the part above it and the ceiling are painted light blue. With this, the combined parts are unified.

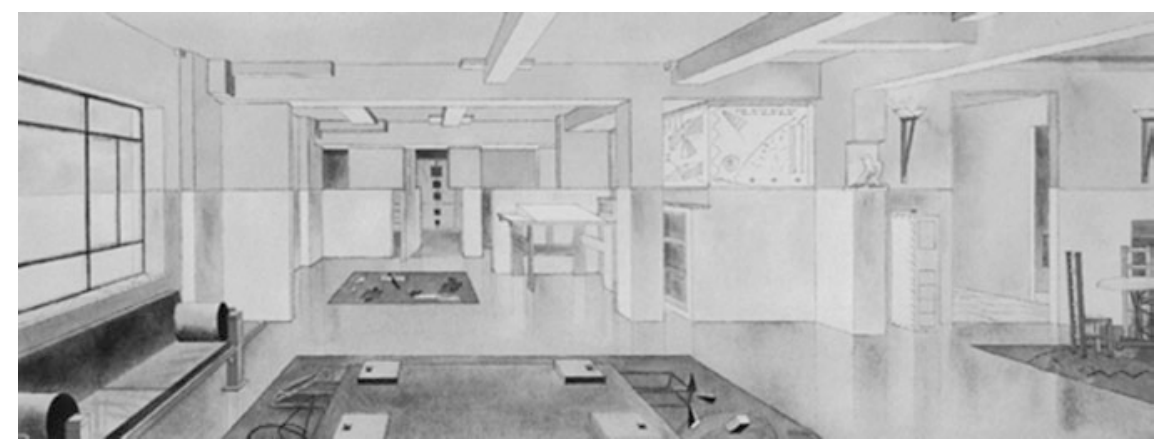

Fig. 1 Perspective of the Cohen Apartment from living room toward study and bedroom. Steven Holl Architects (SHA), 1983 (Holl 2012, 22) 
Parallels can be drawn from the above with some of the tenets of the Dutch group De Stijl. On the one hand, the refining of shapes down to their fundamental components: lines and planes. On the other, a taste for straight angle geometry, present on walls and in the furniture. In this regard, the front of the bedroom closet should be noted, whose composition is based on squares and rectangles of various sizes, recalling the neoplastic paintings of members of the group such as Theo Van Doesburg. ${ }^{1}$

For the interior renovation of the MoMA tower apartment in 1987, Steven Holl also started from a simple geometric concept: the organisation and distribution of the various elements following the directions of the coordinate axes $\mathrm{X}, \mathrm{Y}$ and $\mathrm{Z}$. Therefore, the walls located along the $\mathrm{X}$ axis are painted entirely charcoal black, while those on the $\mathrm{Y}$ are yellow (perhaps he wanted to create a light/dark effect). The $\mathrm{Z}$ direction is represented by the vertical lines of the furniture, emphasised by two long, narrow lamps in the corners.

This combination of coloured surfaces and lines makes the interior space seem entirely planar, which brings us back to De Stijl and its concept of architecture, especially due to the use of colour to alter the perception of the existing volume, visually reducing the composition of planes. But also due to the overall approach to the interior, including furniture, in order to create a spatial interaction between the parts, in which an object located in one position simultaneously serves as a reference for another. That is, as in neoplastic architecture, each part is visually independent from the other and, at the same time, interacts with the entire composition. In this sense, it is worth mentioning the free-standing wall that separates the dining area from the living area, as well as the access door to the bedroom, made up of a hinged panel with two parts that turn and frame the view of the other 'rotational wall' (in Holl's own words) located behind it. This last one is, in reality, a wardrobe with various doors and drawers that fit together like pieces of a puzzle, creating a highly dynamic effect. The furniture, specially designed for the apartment, includes a dining table with the XYZ direction marked in its centre using a geometric motif reminiscent of the painting Composition $y=2 x^{2} / 5$ with Red (1931) by the sculptor and neoplasticist Georges Vantongerloo (Figs. 2 and 3).

\section{Interior Hinged Space}

Between 1989 and 1991, Steven Holl built a housing in Fukuoka (Japan), starting again from the notion of 'hinged space' for the interior layout of the apartments. The proposal was to carry out an active renovation of the entire domestic habitat,

\footnotetext{
${ }^{1}$ See Van Doesburg, Arithmetic composition, 1929-30.
} 


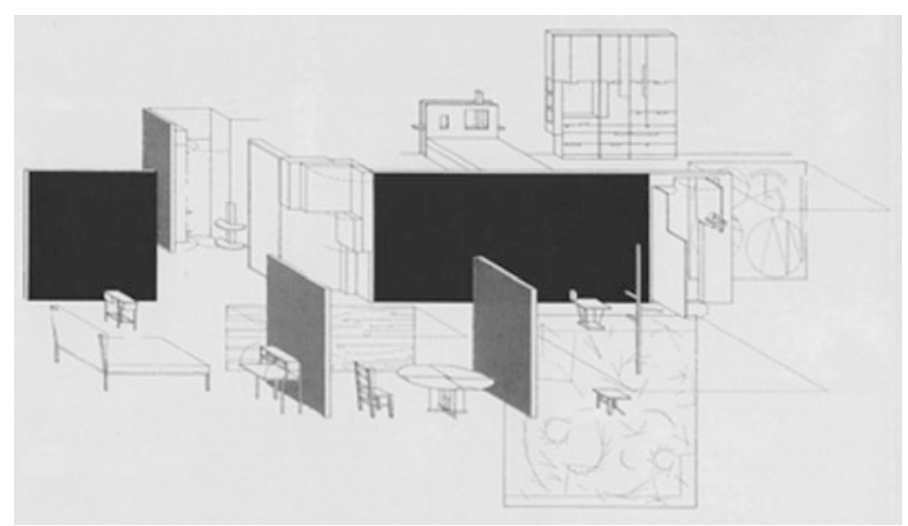

Fig. 2 Axonometry of the MoMA Tower Apartment. SHA, 1987 (Holl 2012, 32)

Fig. 3 Interior view from the door of the bedroom. SHA, 1987 (Holl 2012, 33)

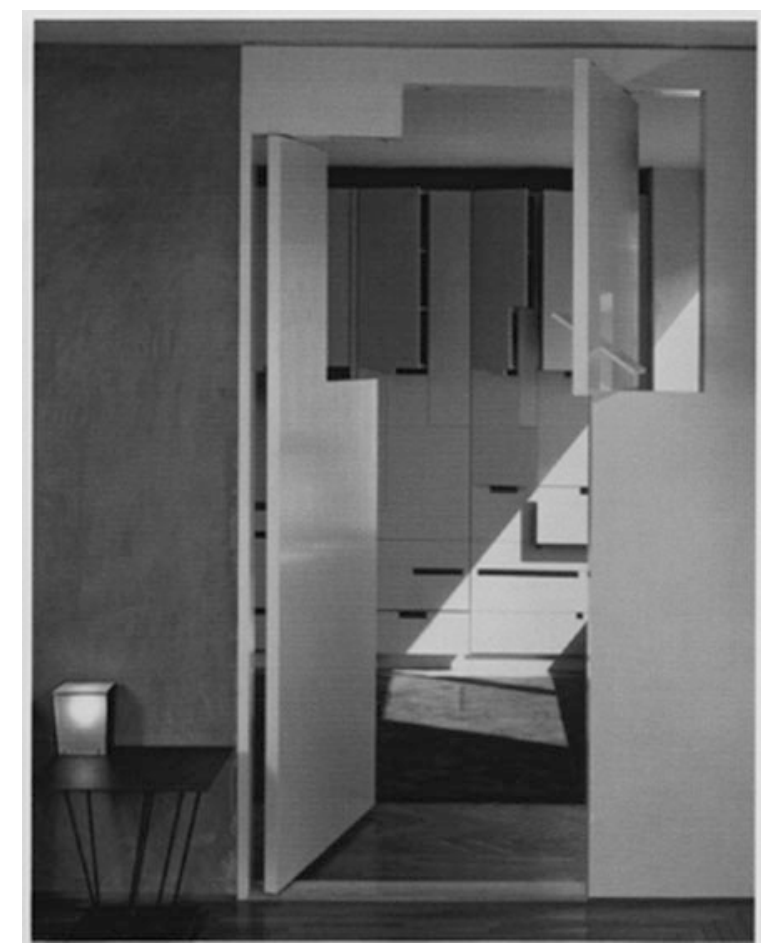

meaning it was possible to make changes or variations depending on the use and needs of the moment. All of this was to make the most of the available floor space; something essential in large cities, where the scarcity of buildable square metres raises prices exorbitantly. 
Therefore, compared to the classic domestic space, defined from the aggregation of separate rooms by fixed walls (in other words, housing with one, two or three bedrooms) the American architect created an interior distribution based on mobile partitions in order to obtain areas whose spatial organisation could be changed to another. In this way, the concept of space based on a defined volume disappeared, bringing us back to neoplastic principle: "The new architecture is anti-cubic, i.e., it does not strive to contain the different functional space cells in a single closed cube".

To do this, Holl used the qualities of the traditional Japanese domestic space as a base and the many ways in which the Japanese make use of it by employing mechanisms such as screens and sliding doors (called fusuma if they are opaque and shoji if they are translucent). Using this approach, he creates a modern interpretation of the Japanese fusuma using pivoting wooden doors, panels and cabinets which can be moved at will, making it possible to unite or divide pieces, according to temporal, cyclical or sporadic changes (bedrooms can be converted into living areas during the day, can be resized when children are born, when children leave home, etc.), thus providing the space flexibility and dynamism. This way, by rotating a number of wall segments, the different areas are no longer compartmentalised so that continuity and smoothness is achieved between spaces (Fig. 4).

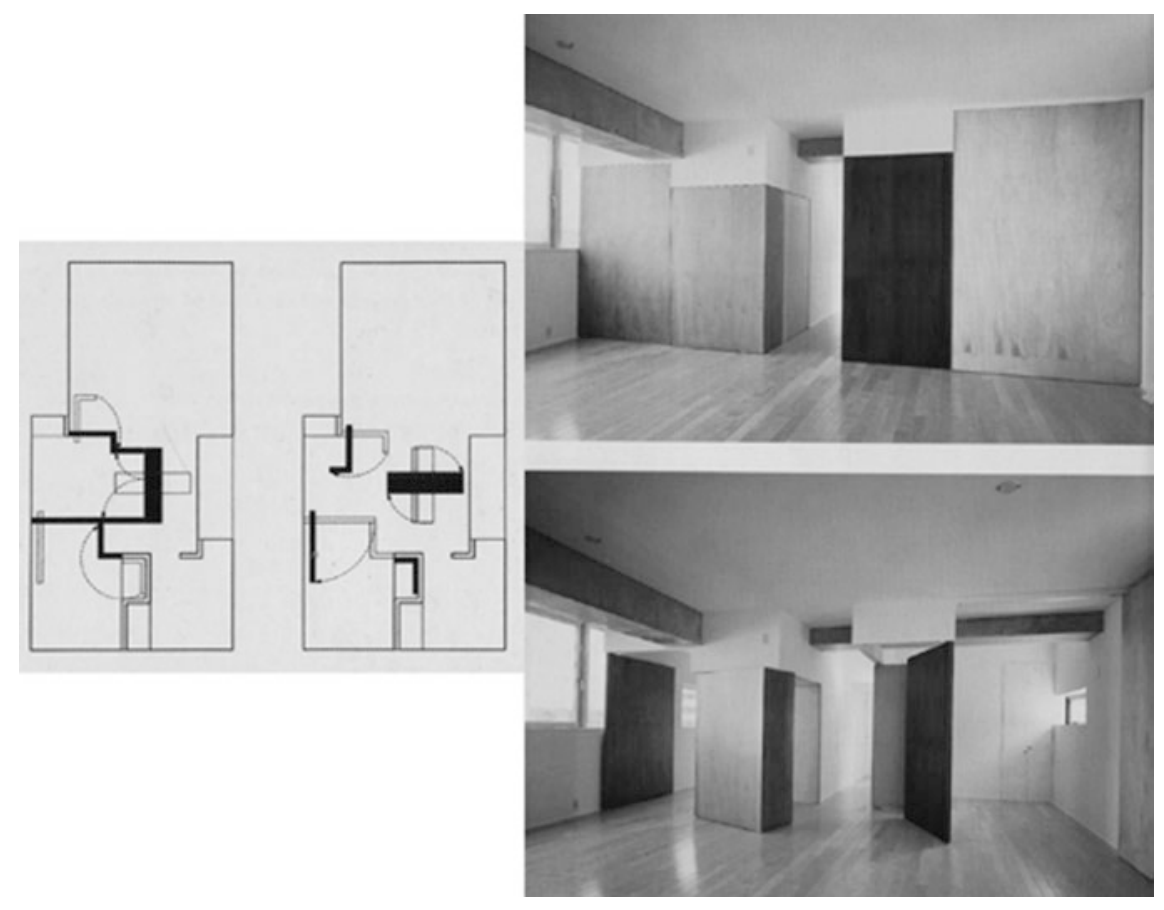

Fig. 4 Diagram of the hinged space and interior views. SHA, Matsuo Photo Atelier, 1990 (Holl 2000, 232-233) 
In some cases, the corners of the rooms can even disappear completely as no two apartments are the same; each is organised according to a different distribution. In fact, each panel is painted following a permutation of colours, from natural wood to black, thus creating different chromatic compositions which help bring the focus to these elements. Overall, the feeling is that of being immersed in a somewhat abstract interior, in which conventional architectural components like walls have been replaced by hinged planes.

\section{Urban Hinged Space}

In 1992, Steven Holl and the artist Vito Acconci were commissioned to restore the old façade of the StoreFront for Art and Architecture, one of the few galleries dedicated to exhibiting the work of young architects in New York City. This project follows the idea of the pivoting panels of the Fukuoka homes, although with some variations. The most important is that, until then, Holl had applied the concept of hinged space solely to domestic interiors. This transformation to a hinged urban space is expressed in the phrase "rethinking hinged space" that appears in the concept diagram of the project (Fig. 5).

Located on the corner of a block, the gallery is actually a long, narrow wedge where the length of the façade is the dominant dimension. Given that the previous exhibitions held were characterised by multiple cuts and layers of paint that had been accumulated on this wall, it did not seem advisable to design something that implied any permanent treatment of it. Similarly, Holl and Acconci were interested

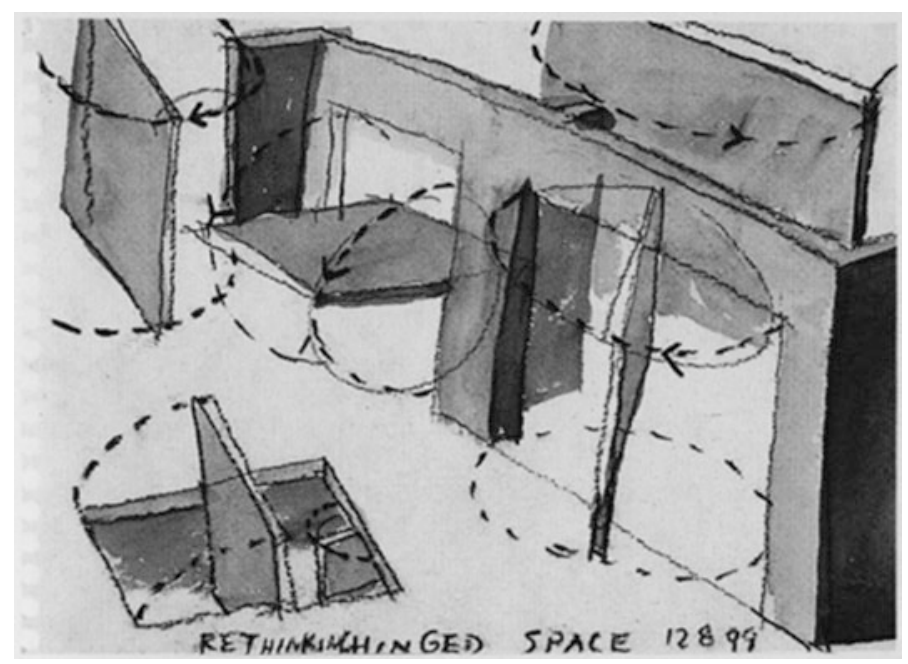

Fig. 5 Concept diagram of the perforatedhinged façade. SHA, 1992 (Holl 2000, 234) 


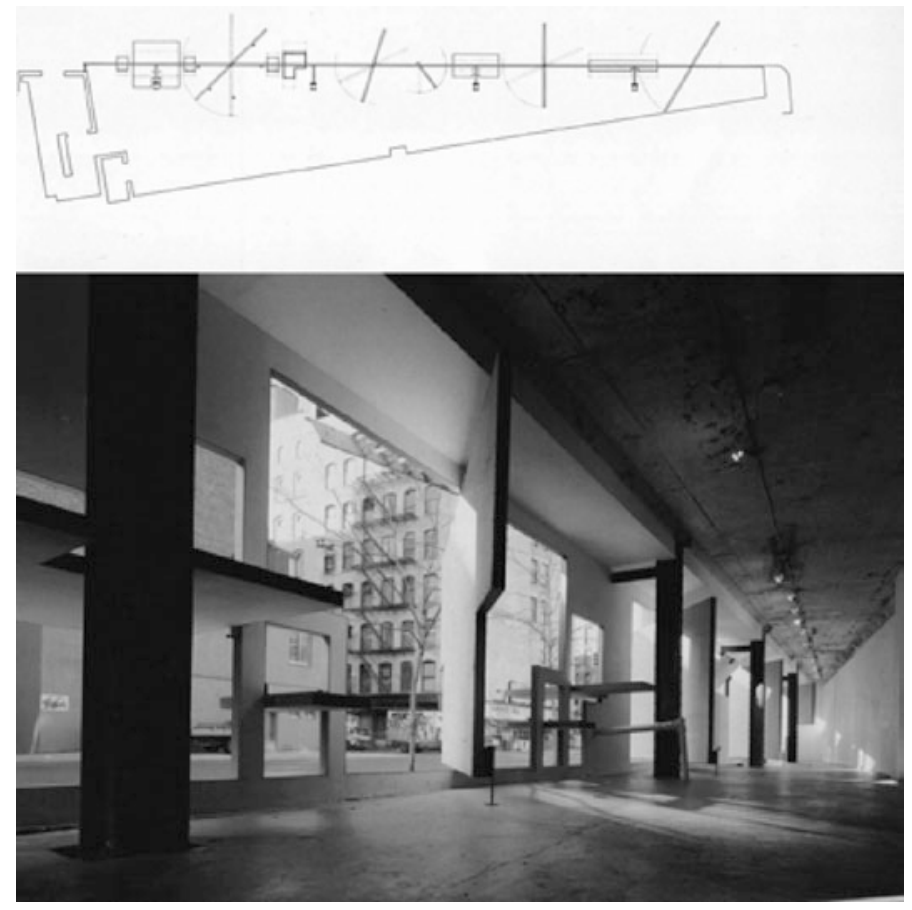

Fig. 6 Final plan project and interior view with the movable panels. SHA, 1993 (Holl 2003, 190)

in achieving an interactive and dynamic exhibition space, a meeting point between the visitor and the artist (conceptual art does not want passive spectators) (Fig. 6).

Based on this, the strategy was to drill into the entire façade wall, inserting twelve pivoting panels made of a composite material (a mixture of concrete and recycled fibres) of various shapes and sizes, which would rotate horizontally or vertically to open the gallery directly onto the street. In this way, they created, firstly, various possible façades depending on the different positions of the panels (even serving as doors, tables and benches), transforming a planar element into a tri-dimensional composition made up of "a multiplicity of planes: again the plane". The description corresponds to the vision of neoplastic architecture and more specifically, Piet Mondrian.

But furthermore, when the panels are opened up, the façade disappears, and with it, the existing division between the interior space and the street. In 1923, Van Doesburg had written: "The new architecture has disrupted the wall and, in so doing, destroyed the division between inside and outside". ${ }^{3}$ Resemblance to the

\footnotetext{
${ }^{2}$ The italics correspond to the original text (Mondrian 1983).

${ }^{3}$ The quote is part of the manifesto 'Towards a Plastic Architecture', published in De Stijl magazine in 1924.
} 
Storefront project is evident. Therefore, the previously private area of the art world expands outward to the general public: life imitates art and art imitates life, just as in the neoplastic ideal. In conclusion, if the main function of a façade is to create a barrier that separates the interior from the exterior space, this new façade, according to Kyong Park, director of the gallery, is "no wall, no barrier, no inside, no space, no building, no place, no institution, no art, no architecture, no Acconti, no Holl, no Storefront" (Holl 2003, 184).

\section{Chromatic Space}

From a physics standpoint, we can describe colour as a property of light, which depends on the wavelength. However, in 1810 Johann Wolfgang von Goethe opposed this purely scientific view in his treatise 'Theory of Colours', proposing that colour also depends on our perception (an aspect forgotten in Newtonian theories) and placing special emphasis on brightness and contrast as determinants of this fact. Later, discoveries regarding the way in which the brain interprets colours confirmed this.

Steven Holl echoes these ideas in his book Parallax, in speaking of what he calls 'chromatic space', referring to this double aspect which includes the objective and the subjective, combining concept and feel. This scientific and aesthetic interest in light and colour shown by the architect, in addition to other key elements like geometry and material, is one of the characteristics of his work, as it gives it a determining value in shaping the architectural space. In his writing "Idea and phenomena", he states: "Space remains in oblivion without light. Light's shadow and shade, its different sources, its opacity, transparency, translucency, and conditions of reflection and refraction intertwine to define or redefine space" (Holl 2003, 90).

Similarly, chromatic space is activated using light beyond the painted surface of a wall or the actual tone of the material, generating halos of colour that tint the surrounding environment through reflection. Thus, by using different systems and types of light, chromatic fields are created that define planes, define volumes and define spaces. In short, it is the space itself and not just the surfaces that surround it, which acquires chromatic qualities.

Holl's interest in the effects of light together with architecture is clearly shown in the Chapel of St. Ignatius, but is manifested in the systematic use of watercolour as a representative medium, and from here other phenomenological considerations may come about, something evident in his Finnish relationships, particularly in the empathy felt by J. Pallasmaa in terms of the user's experience of architecture: "Watercolors allows you to make bodies of light, to go from the bright to the dark. When I am making a series of perspectival views through a series of spaces and thinking about light, watercolor is a better media than line drawing" (Holl 2003, 23) (Fig. 7). 


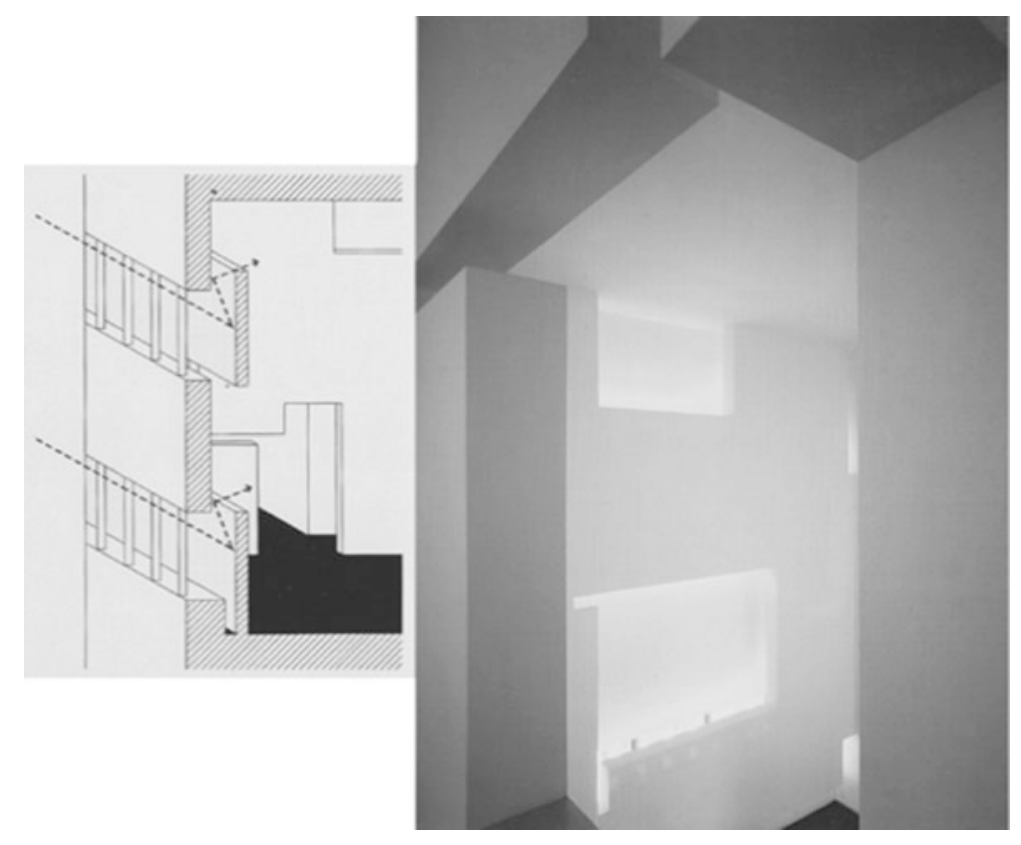

Fig. 7 Colour projection diagram with daylight and view from second level. SHA, 1992 (Holl 2000, 164-165)

In 1991, the creation of a chromatic space was the central concept in the renovation of the offices of the multinational company D.E. Shaw in New York, located on the top two floors of a skyscraper in downtown Manhattan. This project is quite similar to the work of the American artist James Turrell, characterised in turn by the key elements of light and space.

The fact that the firm D.E. Shaw works in managing financial assets helped Holl to establish an analogy between the intangible world of a company working around the clock in the stock market and the design concept, which was based on the placement of colour sources just as invisible to the viewer. This is achieved using wall panels strategically located and painted with bright colours, which act as diffuser colour screens when light strikes them.

To this end, the American architect converted a double-height lobby with access to the offices into a sort of cube within a cube. On the inner walls of the central structure built with plasterboards, a series of openings and grooves at certain points were made, acting as light modulators. To that effect, at the rear of these partition walls, a colour layer was applied which is hidden to the visitor when within the space and is projected to the rest of the surface through reflection, both with daylight and artificial light, thereby creating chromatic reflections, framing especially the holes that were made. To increase the intensity of the reflected colour, fluorescent paint was used. 
With all of this, we can once again find common features with Neoplasticism, mainly in two aspects. Firstly, the use of colour as a key element when defining space; this brings to mind the words of Mondrian: "Neoplastic architecture requires colour, without which the plane cannot be a vital reality for us". Secondly, the cuts in the wall in turn serve to accentuate the perception of the interior space as the sum of intertwined surfaces. Therefore, we can conclude that cutting in Steven Holl's architecture has a similar purpose to colour in neoplastic architecture: in both cases they serve to break down volume on planes, breaking with the traditional architectural notion of enclosed and cubic space. For these reasons, we can once again turn to the explanation of the architect himself, standing against post-modernism but also the modern homogeneous and undifferentiated space: "I thought that light, texture, detail, and overlapping space, constituted a meaning that is silent and stronger than any textual manipulation" (Holl 2003, 15).

In the case of the Sarphatistraat offices located on the Singel canal in Amsterdam, a chromatic space was also achieved by using sparkling colours placed at random, which is particularly successful at night when the light inside the building projects dense blocks of colour floating in the water, painting the canal with the reflection (Fig. 8).

The project itself, carried out between 1996 and 2000, involved the renovation of an old office building plus the construction of a pavilion, designed to accommodate

Fig. 8 Night view of the pavilion. SHA, 2000 (Holl 2003, 190)

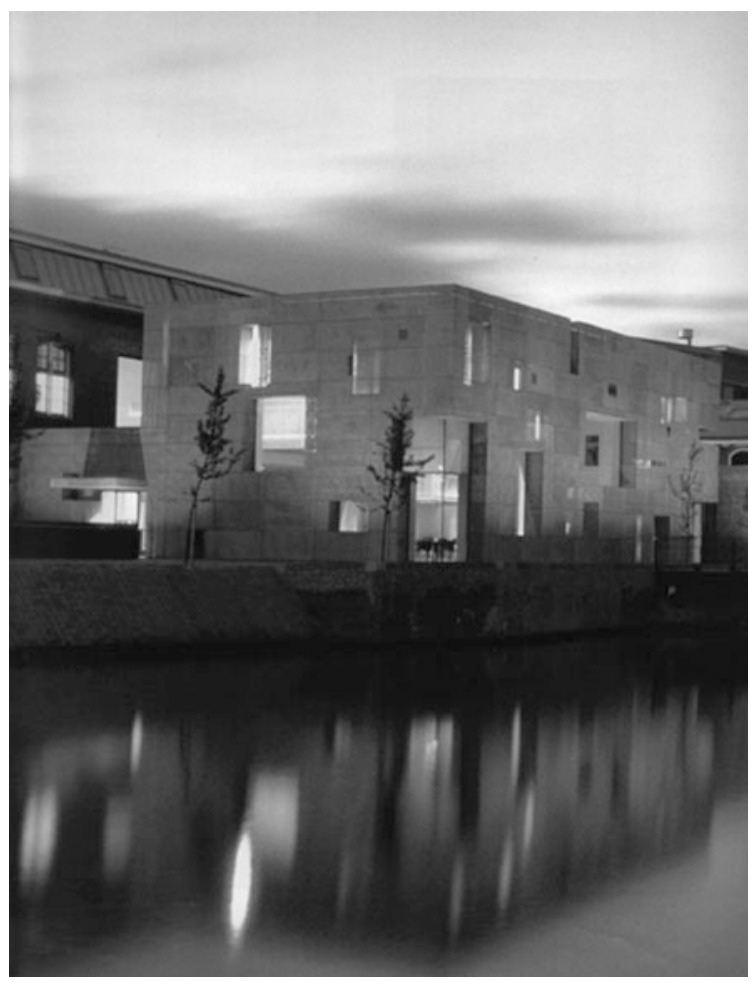


activities ranging from public meetings to theatrical performances. In the case of this last instance, Holl was inspired by both science and music, by mixing the rational and mathematical form of the 'Menger sponge' (a figure full of holes that are repeated in increasingly smaller sections, to the extent that the volume approaches zero and the area infinity) and the randomness of the musical composition "Patterns in a Chromatic Field" by Morton Feldman. The result is an asymmetrical cube-shaped building, riddled with rectangular openings of different sizes, arranged haphazardly in the three dimensions of space, giving it a porous nature. This notion is reinforced by the succession of layers of perforated panels on the façade, made of materials ranging from plywood and aluminium in the interior to copper on the exterior, which act as screens, filtering the light from the openings. Also, squares of fluorescent paint in various hues and of various sizes arbitrarily distributed throughout the different strata of the façade are incorporated to add colour which is enhanced in certain places by lights. There is therefore a permeable porosity in light and reflections, creating a chromatic space changing from the inside out, since the colour increases or decreases in intensity depending on the time of day and type of light. It also addresses planar porosity in which volumes are formed based on the addition of surfaces (Fig. 9).

Some critics have compared Holl's pavilion (located, by the way, in the country of De Stijl's origin) to a pattern in a Mondrian painting. The abstract character of the façade, originating from the asymmetric and harmonious effect of the openings and fluorescent squares, definitely brings the experiments of neoplastic architecture, which used planes and colours, to mind.

Another example of spatial abstraction, about which Steven Holl also speaks of 'planar porosity' (Holl 2000, 318) is the University of Iowa Art and Art History

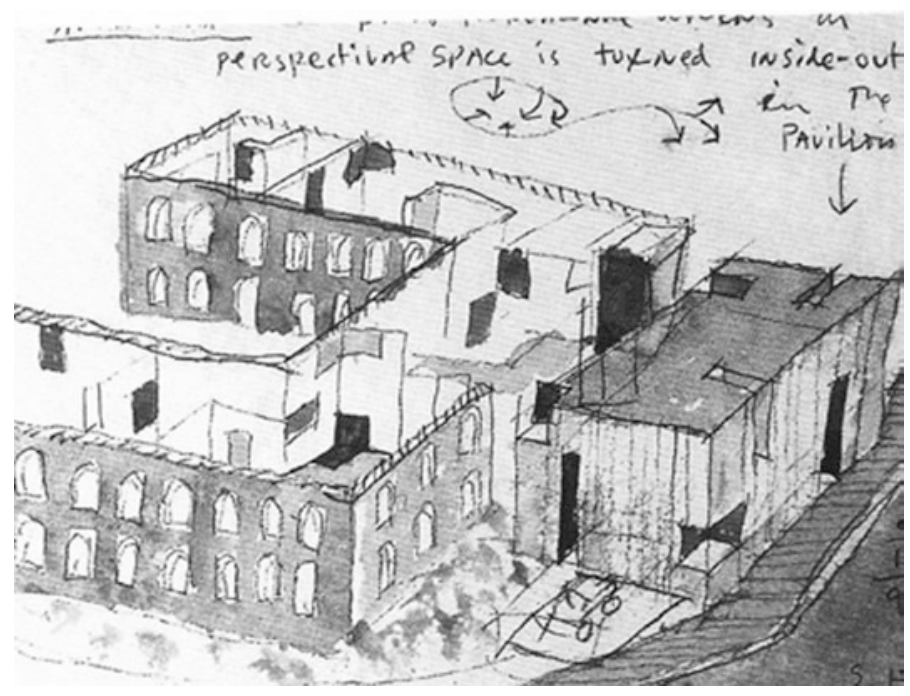

Fig. 9 Initial concept diagram with the colour screens. SHA, 1996 (Holl 2006, 193) 

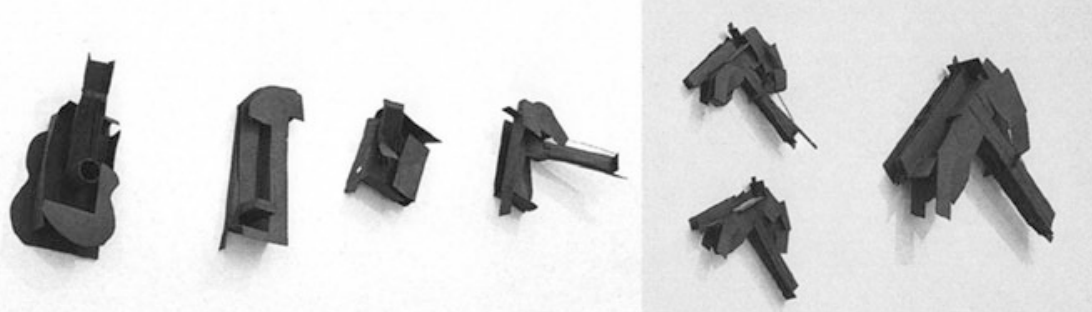

Fig. 10 Series of transformations based on Picasso's sculpture. SHA, 1999 (Holl 2003, 428)

building, a project carried out between 1999 and 2006. Initial studies with models show a sequence of planar constructions whose surfaces are joined together by hinged sections, inspired by the Picasso cubist sculpture Maquette for Guitar from 1912 (Fig. 10).

Lastly, the importance of concept diagrams in formalising Steven Holl's architecture should be noted for their power to capture the essence of each project and their role as an engine driving the design process. In conclusion, his work and method have clear pictorial characteristics and qualities, which come directly from his decision to not use computer graphics techniques in the initial design phase of a project.

\section{References}

Holl, Steven. 2000. Parallax. Basel: Birkhäuser.

Holl, Steven. 2003. Steven Holl: 1986-2003: (in search of a poetry of specifics thought, matter and experience=hacia una poética de lo concreto, pensamiento material y experiencia). Madrid: El Croquis.

Holl, Steven. 2006. Luminosity/porosity. Tokyo: Toto Shuppan.

Holl, Steven, and Yukio Futagawa. 2012. Steven Holl. Tokyo: A.D.A. Edita.

Mondrian, Piet. 1983. La nueva imagen en la pintura: la realización del neoplasticismo en la arquitectura del futuro lejano y de hoy. Murcia: Colegio Oficial de Aparejadores y Arquitectos Técnicos de Murcia.

\section{Author Biography}

M. Teresa Díez Blanco Architect with a degree from ETSA in Barcelona. She has been a design professor in higher education since 2003, with a speciality in interior design. She received a certificate of research proficiency from the doctorate programme in Visual Communication in Architecture and Design. Her preferred area of research is neoplasticism and its influence on current architects. She has written articles on architectural rendering. She is currently writing her doctoral thesis, under the supervision of the doctor of architecture and professor Antonio Millán-Gómez (ETSAB_UPC). 